\title{
SEMBLANZA DE DON TOMÁS CEKÁLOVIC KUSCHEVICH
}

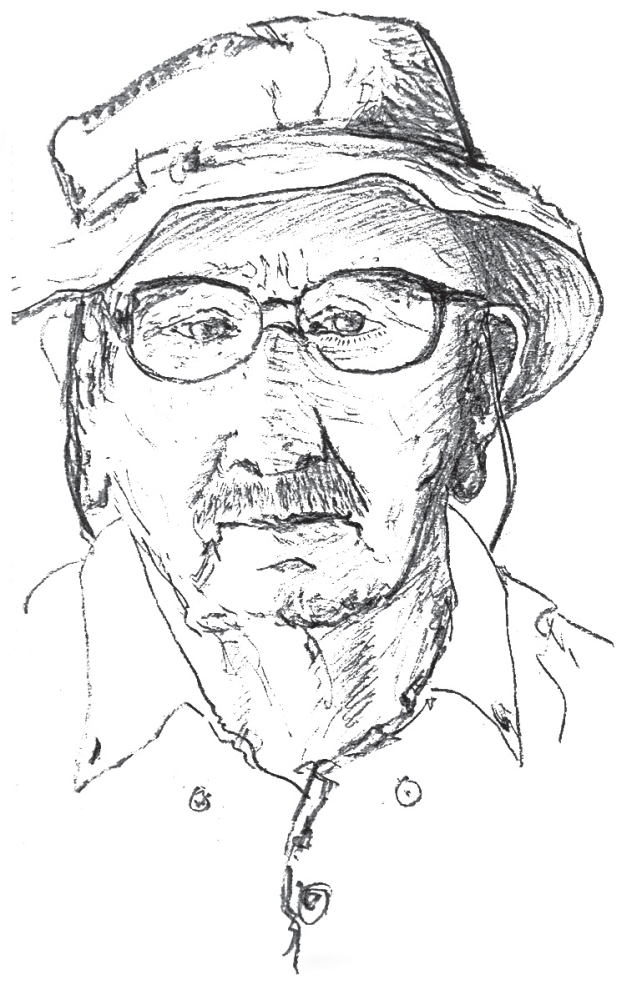

Por Medardo Urbina Burgos Médico Cirujano y Licenciado en Biología.

Don Tomás Cekálovic Kuschevich dejó de existir el 04 de enero de 2013 a la edad de 84 años. El profesor Victor Hugo Ruíz, de la Facultad de Ciencias Naturales de la Universidad de Concepción, me lo contó varios días después de esa aciaga fecha. Sentí no haberlo acompañado en su último viaje de despedida, sobre todo porque éramos amigos.

Conocí a Don Tomás en 1969 a poco de llegar a Concepción. Yo era un estudiante de primer año la carrera de Licenciatura en Biología cuando acudí a la casa que él tenía en calle Aníbal Pinto. Me llevó Sergio Erices Castro, un muy apreciado amigo Antropólogo que en ese entonces trabajaba en el Museo de Concepción. Sergio Erices quería contactarnos pues a ambos nos interesaban los "bichos" y don Tomás era entomólogo y además experto en escorpiónidos, pseudoescorpiónidos, solífugas y solpúgidas, arácnidos sobre los que ya había publicado numerosos trabajos científicos. Esa noche hablamos sobre algunos insectos de Chiloé sobre todo acerca del Ceroglossus ancudanus el "peorro de Chiloé". Era de noche cuando regresé a mi hogar universitario.

Y nos seguimos encontrando, ya sea por mis visitas frecuentes al Museo de Zoología de la Universidad de Concepción, en el que él era el Curador, o por las publicaciones de la revistilla "Chilhué" de los estudiantes chilotes, en la que él colaboró con algunos artículos como "Los Escorpiones de Chiloé" y otros, y más tardíamente al publicar alguno de los artículos en los que ambos fuimos autores o coautores, como la nota del registro más austral del mundo del Peripatus encontrado por Don Tomás en un bosquecillo en las inmediaciones de Chacao. Su actitud y bonhomía nunca cambiaron. Don Tomás fue siempre igual: amable, sencillo, estudioso, exigente consigo mismo en la rigurosidad científica de cada uno de sus trabajos: humilde - tal vez demasiado humilde -. Intentaba pasar inadvertido entre la muchedumbre, a pesar de su tremendo curriculum como investigador científico y a pesar del reconocimiento internacional de su aporte a la Ciencia, seguía expresando humildad en sus actos cotidianos.

Fui varias veces a su casa - ahora en calle Santa Lucía en el barrio Pedro de Valdivia en Concepción - y conocí a cada uno de los miembros de su familia. A la Sra. Norma Bahamonde, magallánica como él pero de ancestros chilotes, gentil, amable y sencilla como su esposo y quien fuera - durante su juventud - bailarina de ballet clásico en Punta Arenas. Y a sus hijos: Tomasito, el mayor quien a 
temprana hora de su adolescencia perdió la vida en forma trágica. A Nadica, quien fuera una brillante alumna en la carrera de Técnico Veterinario, donde yo hice por corto tiempo las clases de Anatomía Comparada; y finalmente a Wladimir, quien fue amigo de mi hijo Mauricio desde la niñez y ambos, por caminos separados, terminaron estudiando Ingeniería. No he de olvidarme de la madre de Don Tomás, la Sra. Elsa Kuschevich Westermann quien se vino con su hijo a Concepción desde Punta Arenas, después de enviudar y una vez que el Dr. José Stuardo Barría, a la sazón Director del Departamento de Zoología del Instituto Central de Biología de la Universidad de Concepción, le ofreciera a don Tomás un cargo en el Departamento, por allá por 1966, en virtud de sus talentos como investigador autodidacta, gran observador de los fenómenos naturales, destacado entomólogo y fotógrafo.

En efecto, don Tomás -que había nacido en Punta Arenas en 1928- fue desde niño un inquieto explorador. Con mucho esfuerzo, en su temprana adolescencia, ahorró para adquirir una bicicleta con la que efectuaba diversos recorridos por las inmediaciones de su ciudad natal. Conoció así todos los senderos y rutas que lo llevaron a diversos extremos de aquellas tierras australes: a la orilla del mar, a los altos cerros de la Cordillera de Darwin, a Cabo Dungenes, al Fuerte Bulnes, a Puerto Natales, a las Torres del Paine y a la Cueva del Milodón, por mencionar sólo los lugares más conocidos. Fue filatelista y numismático y recolector de insectos desde pequeño.

En ese tiempo conoció al padre de la Congregación Salesiana de Punta Arenas Alberto D'Agostini, Director del Museo Salesiano y gran andinista y explorador de las cumbres andinas de la Patagonia, además de excelente fotógrafo y escritor. Don Tomás me contó que un día domingo cualquiera del mes de marzo, cuando él tenía unos 12 años, tomó el bus hacia Puerto Natales con la finalidad de colectar insectos en las inmediaciones de la Cueva del Milodón y se sentó junto él en el bus, un señor algo gordito, de buen aspecto y muy amable, con el cual entabló una interesante conversación. Al regreso a Punta Arenas al filo de la tarde, en el mismo bus volvió a sentarse con él el mismo señor, quien lo invitó a visitarlo en el Colegio Salesiano de Punta Arenas a fin de regalarle un libro. Cuando acudió a la cita a los pocos días, se encontró con que el señor gordito que lo acompañó a Puerto Natales, era el Rector del Colegio Salesiano de Punta Arenas y nada menos que el gran Alberto D'Agostini, quien le regaló el libro de su autoría: "Andes Patagónicos" dedicado y autografiado de su puño y letra.

Resulta curioso que a la edad de su adolescencia Don Tomás ya tenía intercambio epistolar con diversos especialistas en insectos de varias partes del mundo, con los cuales intercambiaba ejemplares y le ayudaban a identificarlos por sus nombres científicos, Phyla, Clase, Familia o género. Así supieron de él los directores de la ENAP en Punta Arenas y le ofrecieron un cargo en el Laboratorio de Micropaleontología, para el estudio de microorganismos fósiles (Foraminíferos) presentes en los "testigos" extraídos de la profundidad de las capas de la Tierra de los fondos magallánicos, por los trépanos de muelas de diamante de las torres de exploración petrolíferas. Corrían los años iniciales de la década de 1950. Así don Tomás se familiarizó en el manejo del microscopio y en la identificación de una enorme variedad de formas de microorganismos fósiles o sus tecas, cuya presencia en las capas submarinas señalaban la probabilidad de encontrar petróleo (en ese caso las torres deberían seguir perforando) o la evidencia de capas inertes en las que sería imposible encontrarlo (en ese caso debería suspenderse las perforaciones en esos sitios).

El Dr. José Stuardo Barría Director en aquel entonces del Departamento de Zoología de la Universidad de Concepción, conoció a don Tomás en ese preciso tiempo, durante una detención en Punta Arenas, del equipo de biólogos integrantes de una de las primeras Expediciones Antárticas chilenas. Supo de primera fuente sobre sus talentos, observaciones, identificación de especies y habilidades en el manejo de frágiles ejemplares de insectos y otros Arthropoda, amén del hábil manejo del microscopio, y vio en él un valioso investigador para la universidad y un promisorio futuro en el campo de la Ciencia, en lo que el Dr. Stuardo no se equivocó en un ápice (Véase el Curriculum Vitae de Don Tomás Cekálovic Kutschevich).

Su arribo a Concepción y a la universidad fue el año 1966 y una de las primeras labores a la que se abocó fue reanudar las publicaciones del Boletín de la Sociedad de Biología de la universidad, que hacía varios años no se editaba un número. La revista estaba en ese entonces a cargo del Dr. Concha de la Escuela de Medicina. Don Tomás se puso en contacto con él y le propuso varios pasos que dieron como resultado la reanudación de las publicaciones científicas de nuestra universidad, revista que no ha sido interrumpida desde aquel entonces. En aquellos años llegó al Departamento de Zoología el Dr. Roberto Donoso-Barros, médico cirujano dedicado especialmente al estudio de los vertebrados y dentro de ellos a la Herpetología primero ("Reptiles de Chile", Ediciones de la Universidad de Chile, 1966) y posteriormente al estudio de los mamíferos, especialmente las ballenas de nuestros mares ("Contribución al Conocimiento de los Cetáceos vivientes y fósiles del Territorio de Chile", 1975, obra póstuma publicada en GAYANA con la colaboración de los profesores Hugo Iván Moyano e Iván Benoit bajo la responsabilidad del Dr. Jorge N. Artigas, como editor). Don Tomás acogió muy bien al Dr. Donoso a su arribo a la ciudad y se estableció entre ambos una amistad más allá de los cánones profesionales del estudio de la Ciencia. Don 
Tomás me contó que cada tarde - camino a su domicilio en Chiguayante - el Dr. Donoso gustaba pasar a saludarlo en su casa en calle Santa Lucía para conversar sobre el curso de sus respectivas investigaciones y descubrimientos, a tomar onces y a jugar una partida de naipes, para luego retirarse a su domicilio - algo entrada la noche - en su conocida y ya desvencijada citroneta.

Don Tomás jubiló como Curator del Museo de Zoología de la Facultad de Ciencias Naturales y Oceanográficas de la Universidad de Concepción en 2008, y desde ese entonces se hizo más frecuente su presencia en mi estudio médico, ya sea por alguna dolencia propia de la edad, como por el intercambio de información respecto de nuestras inquietudes en los más variados temas ya sea su valioso conocimiento de las especies de artrópodos de Magallanes y la Patagonia chilena, como la extensa colección de fotografías y diapositivas acuciosamente clasificadas y ordenadas que logró acumular durante su fructífera vida, o bien por causa de la temática chilota, que nunca estuvo ausente en nuestras conversaciones, amén de sus interesantísimos relatos de tantas experiencias valiosas que vivió en Magallanes especialmente, que fueron tema de un libro que él desgraciadamente no alcanzó a ver publicado. Con todo, estuvimos con don Tomás en la dolorosa pérdida de su hijo mayor (Tomasito), en la de su querida madre y en la despedida de su querida esposa, cuya enfermedad terminal me cupo la dolorosa misión de identificar. También logramos ayudarlo a resolver algunas dolorosas lesiones gástricas sufridas en el último tiempo, cuyos estudios no determinaron presencia de enfermedad grave. Sin embargo en el último episodio de neumonía que significó una rápida hospitalización y su deceso en menos de 24 horas, desgraciadamente no pudimos estar presentes, ni supimos del episodio sino varios días más tarde.

Nuestras secretarias lo estimaban sinceramente por su trato afable, su erudición, su facilidad expresiva, por las entretenidas historias que siempre les contaba mientras esperaba atención médica y sobre todo por su sencillez y humildad en el trato. Por mi parte, debo reconocer su excelente disposición a colaborar en cada una de las materias en las que se solicitó información (su biblioteca era magnífica y él sabía siempre encontrar las información precisa) para diversos trabajos que lograron publicarse o que permanecen aún en pre-prensa, y debo manifestar mi agradecimiento a su personalidad siempre dispuesta a ayudar, tanto a los vecinos a cuyas necesidades siempre estaba atento, como al Club Croata al que pertenecía de corazón o a las actividades culturales de los chilotes, a las que siempre asistió y contribuyó con su bien fundamentado conocimiento. Nos sentimos orgullosos de haber compartido la amistad de tan valioso ser humano, cuya sencillez y humildad no aminora la valiosa contribución a la Ciencia expresada en 88 trabajos de su autoría publicados por diversas y prestigiosas revistas científicas, en temas especialmente entomológicos o sobre arácnidos, especialmente Escorpiónidos, Pseudoescorpiónidos, Opiliónidos y Solífugas o Solpúgidas, grupos que acapararon su atención como especialista.

Como editor del Boletín de la Sociedad de Biología de Concepción, -revista que como ya hemos dicho, hasta aquel entonces estaba dedicada a trabajos del área médica y permanecía inactiva por varios años-, Don Tomás le dio un vigoroso impulso con la inclusión de trabajos de investigación en el área de la Zoología. Su valiosa experiencia en recolección de ejemplares de las más variadas especies en los más diversos ambientes le llevaron a desarrollar una habilidad innata que permitió a la Universidad de Concepción y a su Departamento de Zoología, enriquecerse con cuantiosas colecciones de artrópodos de las más diversas especies. Extraordinario aporte el de Don Tomás en la obtención de especies nuevas desde el humus de sotobosque gracias al uso de los más diversos implementos, algunos de los cuales de extraordinaria sencillez y eficiencia, que él mismo diseñaba y fabricaba. Así, con el material colectado por él, se han descrito más de 350 nuevas especies, 42 de las cuales fueron dedicadas a él por los más diversos autores de todo el mundo y llevan en consecuencia el nombre "cekalovici". Dicho material se encuentra depositado como Typo o Paratypo en los museos de Zoología de varias universidades del mundo, pero especialmente en el Museo de Zoología de la Universidad de Concepción, donde trabajó por más de 50 años. Sea esta nota un merecido reconocimiento póstumo para un notable científico autodidacta que fue nuestro querido y respetado amigo, del que siempre estaremos agradecidos y al que esperamos mantener en el más grato lugar de nuestra memoria.

\footnotetext{
Dr. Medardo Urbina Burgos Médico Cirujano y Licenciado en Biología
} 